\author{
Н. Б. Мечковская \\ Белорусский государственный университет \\ (Беларусь, Минск) \\ nina.mechkovskaya@gmail.com
}

\title{
НОМИНАТИВНЫЙ И КОММУНИКАТИВНЫЙ УРОВНИ ЯЗЫКОВОЙ СТРУКТУРЫ: В КАКОЙ МЕРЕ ИМ ПРИСУЩИ СВОЙСТВА ВОСПРОИЗВОДИМОСТИ И ИДИОМАТИЧНОСТИ ЕДИНИЦ?
}

В статье показано, что свойства воспроизводимости и идиоматичности единиц имеют место на всех семантических уровнях языковой структуры (лексемы, словосочетания (в основном подчинительные), предложения), однако степень их присутствия на разных уровнях разная. Для слов названные свойства практически облигаторны: все слова, исключая потенциальные, воспроизводимы и идиоматичны, при этом непроизводные слова полностью идиоматичны, производные - частично идиоматичны, причем мотивированность морфемных дериватов носит абстрактный логико-грамматический характер (в отличие от наглядно-образной мотивированности у фразем). В синтагматике слов фраземы составляют незначительное меньшинство словосочетаний, однако их количество в абсолютных цифрах, с учетом массы неидиоматических и слабоидиоматических фразем, велико и, по всей вероятности, превышает количество лексем. На уровне предикативных единиц относительное и абсолютное количество воспроизводимых высказываний минимально (в сравнении с уровнями слов и словосочетаний); свойство идиоматичности характерно для высказываний также в минимальной степени. Идиоматичность предикативных клише создается с помощью семантических механизмов, принадлежащих двум уровням языка - грамматике (фразеологизированность ряда моделей предложения) и лексике (образность или лексико-синтаксическая неузуальность). Названные механизмы не являются специфичными для предикативных клише; они достаточно обычны в свободно создаваемых высказываниях. Пропорции свободно создаваемых и клишированных языковых средств, разные для разных уровней, отвечают разным функциям языка - участвовать в речемыслительных процессах и быть надежным и экономным средством коммуникации.

Ключевые слова: уровневая структура языка, идиоматичность и воспроизводимость в лексике, воспроизводимые словосочетания (фраземы), градация фразем по степени идиоматичности, неидиоматичные и слабоидиоматичные фраземы, воспроизводимые (клишированные) высказывания. 
0. Свойства воспроизводимости и идиоматичности единиц имеют место на всех уровнях языковой структуры, однако степень их присутствия на каждом уровне разная; характер идиоматичности у слов, фразем и коммуникативных клише также различен. Названные различия составляют предмет настоящей статьи.

1. Количественные диспропорции в лексике и в соединениях слов между воспроизводимыми единицами и единицами, которые свободно образуются в речи. Подавляющее большинство слов существуют как готовые (воспроизводимые) номинативные единицы, устойчивые по структуре и значению. Исчезающе малое исключение составляют так называемые «потенциальные слова» (термин Г. О. Винокура) - номинации, созданные говорящим по продуктивным и регулярным словообразовательным моделям для данного момента речи (выпрыгиватель, выступальщик, мусоринка, футболизащия). Это слова «одноразового использования»; их легко создать и так же легко понять, но ни к чему помнить.

В синтагматике речи количественное соотношение между воспроизводимыми и свободно образуемыми единицами обратное тому, которое наблюдается в лексике: неисчислимое большинство соединений слов - словосочетаний и высказываний - создаются свободно и не являются повторением прежде созданных соединений, и только исчезающие малая доля словосочетаний и высказываний не создается в речи, но воспроизводится. Однако эта исчезающие малая доля процента воспроизводимых словосочетаний (фраземы) и воспроизводимых высказываний (паремии, формулы этикета, крылатые фразы, речевые формулы), в силу повторяемости, а также нередкой смысловой весомости и языковой выразительности, маркированы в потоке речи. Говорящие их выделяют, замечают и, бывает, не прочь повторить. "Исчезающе малая доля" воспроизводимых словосочетаний, взятая в абсолютных цифрах, оказывается не такой уж незаметной. По оценке Л.Н. Иорданской и И.А. Мельчука, «люди говорят не словами, а фраземами [...]. Количественно фраземы превосходят слова в словарях примерно в соотношении 10 к 1» [Иорданская, Мельчук 2007: 218]. Эта оценка может удивить, но в ее пользу есть аргументы (см. ниже раздел 3.5). Разумеется, важно, словник какого словаря авторы взяли бы в качестве единицы измерения фразеологического фонда языка.

Телеологический (когнитивный и коммуникативный) смысл представленного количественного распределения воспроизводимых и свободно создаваемых единиц состоит в своеобразном «разделении труда» между лексикой (т. е. широко говоря, парадигматикой речи) и соединением слов (синтагматикой речи). Практически поголовная воспроизводимость лексем обеспечивает стабильность и надежность элементарных референтных компонентов речи. С другой стороны, преобладание в речи свободно создаваемых словосочетаний и высказываний важно для свободы говорящих в осознании нового и в сообщениях о нем. Лексически язык ограничен, однако его синтагматическая свобода преодолевает границы повторяемого. Как писал Пушкин, «язык неистощим в соединении слов».

2. Количество слов, фразем и коммуникативных клише: межуровневое сопоставление. В языках с давней письменной традицией в их больших национальных лексиконах словник насчитывает примерно полмиллиона слов. Эта цифра 
и больше и меньше реального числа циркулирующих в социуме слов, она нуждается в комментариях, но в данном случае важен порядок - количество нулей в числовом разряде.

О количестве фразем и воспроизводимых высказываний приходится судить также по лексикографическим данным - словарям фразем, паремий, изречений, афоризмов, популярных цитат, крылатых слов, коммуникем, речевых формул, выражений “живой речи” и т. п., однако их надежность существенно меньшая, чем надежность словарей при оценке лексических фондов языка. В отличие от словарей слов, составляемых с лингвистическими целями - показать лексические возможности и (обычно) нормы языка, словари клишированных оборотов - это всегда коллекции, составленные на разных основаниях, с разными авторскими и издательскими представлениями об историко-филологической и потребительской ценности разных групп клише. Поэтому трудно сказать, как соотносятся эти сборники готовой мудрости и расхожей экспрессии с языковой реальностью - живой речью современников. Ближе всех к ответу на этот вопрос подошел Г.Л. Пермяков в экспериментах 1970-х гг. по определению русского «паремиологического минимума» (его термин). Он предлагал 100 испытуемым (жителям Москвы и области) по предъявленной первой части пословицы или поговорки дописать ее оставшуюся часть. Выяснилось, что из 540 паремий (также полученных в результате предварительного фильтрующего эксперимента), испытуемые смогли правильно закончить около 300 паремий. Так определился состав и объем активного паремиологического минимума носителей русского языка. В 1985 г. результаты Пермякова были изданы как адресованный немецкому читателю словарь, содержавший 300 русских паремий [Permjakov 1985; см. также Крикман 1986].

Концепция «паремиологического минимума» Г. Л. Пермякова получили развитие в СПбГУ, в разработанном М.Ю. Котовой паремиологическом словаре 9 языков - 8 славянских и английского [Котова 2000]. Русский (исходный) паремиологический минимум был определен в 500 единиц; польских и английских переводных соответствий оказалось на 7-8\% меньше; соответствий в остальных славянских языках - больше. Основания для расширения списка паремий в национальных разделах в словаре Котовой (по сравнению с экспериментальными данными Пермякова) понять, конечно, можно, но важно, что и при таком подходе количество общеизвестных паремий мыслится немногим больше полутысячи.

Разумеется, паремии - это только один, хотя и наиболее яркий разряд коммуникативных клише. Однако есть основания считать, что и весь класс клишированные высказываний, реально используемых в речи, насчитывает едва ли больше тысячи единиц, из которых половину составляют нечленимые, короткие и денотативно смазанные “коммуникемы”. Относительная немногочисленность повторяемых высказываний соответствует семиотической природе предложения в качестве основной логико-синтаксической и коммуникативной единицы языка. Клишированные высказывания противопоказаны продуктивному общению и интеллектуальному поиску. Паремии хороши для эмфазы, для уговоров и внушений, но не 
для логического доказывания и рациональной аргументации. Как советует одна самокритичная паремия у Даля, «Есть ум - живи умом, нет ума - живи по пословице».

3. Градация слов и фразем по уменышению степени идиоматичности их семантики. В обозначении разрядов фразем, дифференцированных по степени идиоматичности (“семантической слитности”), используется терминология В.В. Виноградова (фразеологические сращения, ф.единства, ф.сочетания) [см. Виноградов 1947/1977] и Н. М. Шанского, который обнаружил обширный класс неидиоматических и неустойчивых, однако воспроизводимых словосочетаний, назвав их “фразеологическими выражениями” [Шанский 1963/1969: 84-85].

3.1. Полная идиоматичность непроизводных слов и фразеологических сращений: жаль, красный, хотеть, деньги; точить лясы, притча во языцех, собаку cъесть (в чем, на чем) ('быть знатоком, мастером'). Непроизводные слова по языкам мира составляют 25-30\% лексических фондов. Процент ф.сращений крайне мал, они уходят из употребления, однако в единичных случаях жизнь идиомы поддерживается экспрессией именно алогизма связи ее внутренней формы и узуальной семантики (ср. вешать всех собак (на кого) и т. п.).

3.2. Частичная идиоматичность (логико-грамматическая мотивированность) производных слов. Производные слова, составляя 70-75 \% словаря, создают преобладание в лексике мотивированных знаков, однако, в силу абстрактного логико-грамматического (а не наглядно-образного) характера мотивированности производных слов, их семантика в высокой степени идиоматична. Когда носитель языка семантизирует новое (для себя) производное слово, ему, чтобы лексически конкретизировать грамматическую и словообразовательную семантику слова, требуется, как правило, несколько попыток семантизации. Семантические различия между однокоренными словами закрепляются в сознании людей прежде всего в силу регулярности грамматических и словообразовательных отношений, однако эта связь недостаточно рефлексируется сознанием. Понять образную связь дословного и переносного значения образной идиомы (делать из мухи слона, держать камень за пазухой, сидеть на чемоданах) в большинстве случаев легче, чем понять логику связей между словами внутри гнезда (бегун, беглеи, беженеи, перебежчик, набег, побег, пробежка, разбежка, убежище). Поэтому, кстати, идиоматичность производных лексем (как черта их семантической организации) почти не участвует в создании прагматических коннотаций, эмоционально-экспрессивных и субъективно-модальных. Словообразование служит в первую очередь не прагматике, а задачам номинирования новых объектов мысли.

3.3. Частичная идиоматичность фразеологических сочетаний (високосный год, изъявительное наклонение, кисейная барышня, кромешный ад и т.п.). Хотя один компонент в составе таких фразем выступает в своем словарном значении, однако, в силу семантической и синтагматической недостаточности второго компонента, неясность ф.сочетаний составляет при семантизации бо́льшую загадку, чем неясность образных идиом. Что такое кромешный или окладистый для современного подростка? Для семантизации ф.сочетаний нужна не столько живость 
воображения, сколько известность конкретного слова, иногда термина. В любом языке ф.сочетаний крайне мало, но все же больше, чем ф.сращений.

3.4. Частичная идиоматичность (образная мотивированность) фразеологических единств (закинуть удочку, сматывать удочки, тянуть за язык, прикусить язык и т. п.). В образных фраземах нередко видят основной класс фразем самый многочисленный и репрезентативный. Образные идиомы первыми попали в поле зрения этнографов и фольклористов и надолго определили взгляд на фраземы как на «интересные» средства перифрастической номинации, вторичной по отношению к нейтральному основному обозначению. Ср. синонимы, с помощью которых В.И. Даль характеризует такие образные идиомы, как у него не все дома, одного поля ягода, один как верста в поле, чужими руками жар загребает: у Даля это “окольное выражение, переносная речь, простое иносказание, обиняк” [Даль 1861-1862/1957: 20]. Образные фраземы привлекают максимум внимания говорящих; их любят, как родной фольклор. Есть словари, которые хотя и называются «фразеологические», но принципиально включают только образные идиомы. Однако образных идиом не так уж много: во «Фразеологическом словаре» под ред. А.И. Молоткова свыше 4 тыс., в близком по объему белорусском словаре идиом И. Я. Лепешава 6 тыс.

\section{5. Неидиоматические и слабоидиоматические номинативные единицы:} потенциальные слова и фразеологические выражения. Класс фразеологических выражений - это самый многочисленный разряд фразем, при этом он объединяет самые незаметные фраземы - неидиоматические. В составе ф. выражений все слова-компоненты выступают в своих узуальных значениях (включая и переносные словарные значения), поэтому фразеологичность ф.выражений состоит единственно в их воспроизводимости в качестве “готовых единиц с постоянным составом и значением” [Шанский 1963/1969: 84]. В терминах раннего Мельчука, это “неустойчивые и неидиоматичные” и при этом несвободные сочетания лексем [Мельчук 1960: 79]; в его более поздней работе они названы “квази-идиомами” и “квази-фраземами” [Mel'čuk 1995: 177-179]. В работе [Иорданская, Мельчук 2007: 230-234] они включены в понятие “фразеология” в широком смысле — “все виды несвободных сочетаний двух и более слов’.

Узуальность значений компонентов в составе ф.выражений сказывается в том, что такие обороты легко понимаются говорящими, поэтому они незаметны для лексикографов и нечасто и поздно попадают в толковые словари. В отличие от образных идиом (ф.единств), ф.выражения - это не синонимические средства, нужные для «красного словца», но часть общенародного словаря - основные, общепринятые и часто единственные обозначения вполне определенных и общеизвестных вещей и представлений; ср. воспроизводимые обороты школьных разговоров: внеклассное чтение, годовая контрольная, годовая оченка, группа продленного дня, домашняя работа, задание на дом, заполнить дневник, зарубежная литература, записать в дневник, заполнить дневник, заполнить журнал, классная дама, классная работа, классное собрание, классный журнал, классный руководитель, контрольная работа, контрольное тестирование, контрольный диктант, 
контрольный опрос, окончить четверть, оченка за четверть, первая четверть, работа над ошибками, самостоятельная работа, словарь иностранных слов, учебный год и т.п. ${ }^{1}$. Как можно видеть, отдельных “школьных" слов значительно меньше, чем школьных фразем. Неидиоматические и необразные фраземы особенно употребительны при повседневных градуально-количественных оценках, обычно приблизительных. Этому служит множество таких малозаметные оборотов, как в конечном счете, в конце концуов, в первых рядах, из первых рук, как правило, как раз, любой иеной, минута в минуту, на каждом шагу, на первый взгляд, на первых порах, на скорую руку, не сегодня завтра, ни больше ни меньше, ни много ни мало, один за другим, один на один, от начала до конца, с минуту на минуту, с некоторых пор, с первого взгляда, с первых слов, сколько угодно, то и дело, только что, тут как тут и мн. др. (Подробней см.: [Мечковская 2005: 70-74]. Терминологии и номенклатуры (т. е. средства номинации за пределами общего словаря) насчитывают тысячи воспроизводимых, но не идиоматичных сочетаний, которые благодаря своей двусловности выражают родо-видовые и иные логические связи понятий.

В каких условиях у ф. выражений возникают те семантические особенности, которые можно назвать «слабой идиоматичностью»? Некоторая невыводимость семантики словосочетания из значений компонентов развивается у общеизвестных, частотных и многозначных ф.выражений, сопряженных с целым гнездом тематических близких фразем. Таковы, например, некоторые фраземы с прилагательным уголовный: уголовная ответственность, у. полиция, уголовное дело, у. законодательство, у. наказание, у. право, у. преступление, уголовно-правовой запрет, уголовный закон, у. кодекс, у. лексикон, у. проиесс и т. д. Фразема уголовное право имеет ряд значений: это и отрасль права, и учебный предмет, и название книги, и экзамен, и дифференцирующий компонент в названии кафедры, и специальность конкретного юриста и т. п. У таких фразем обычно есть сокращенные и просторечно-сленговые замены, иногда омонимичные между собой: уголовка, УК, УП и т. п. Обилие синтагматических и парадигматических связей у подобных фразем и делает их значения вне контекста менее определенными.

В целом фразеологический фонд - это отнюдь не синонимическая периферия языка, красочная, но факультативная. Это тысячи воспроизводимых и по-разному несвободных словосочетаний, которые в своем большинстве являются основными обозначениями множества денотатов.

4. Двойственная (синтаксическая и лексико-семантическая) природа идиоматичности большинства коммуникативных клише. В воспроизводимых высказываниях идиоматичность не может быть полной (как это бывает в семантике непроизводных слов и ф.сращений): такое высказывание стало бы смысловым

${ }^{1}$ В Большом толковом словаре русского языка под ред. С. А. Кузнецова (2001) некоторые из приведенных оборотов даны как типичные примеры словосочетаний; для трех фразем (группа продленного дня, классная дама, самостоятельная работа) даны пояснения (т.е. лексикограф осознает, что “сами по себе” эти словосочетания непонятны, иначе говоря, в какой-то мере идиоматичны); некоторые из оборотов не вошли в словарь ни как примеры типичного словоупотребления, ни как фраземы. По отношению к ф.выражениям такие колебания словарей характерны. 
провалом в разговоре. С другой стороны, есть коммуникативные клише, полностью неидиоматичные (Поживем увидим; Старость не радость; Блажен, кто верует). Таким образом, идиоматичность присуща только части воспроизводимых высказываний, и в этом классе клише она всегда носит частичный характер. Идиоматичность коммуникативных клише создается с помощью семантических механизмов, принадлежащих двум уровням языка — грамматике (фразеологизированность ряда моделей предложения) и лексике (образность или лексико-семантическая неузуальность).

\section{1. Синтаксическая фразеологизированность предикативных моделей ча-} сти коммуникативных клише. Для клишированных высказываний, построенных по фразеологизированным моделям (Не тут-то было; Что за чушь!; Не приведи госnодь!), характерна эллиптичность и свернутость, что сближает их с понятием «конструкция» в «грамматике конструкций» Ч. Филлмора [Fillmore et al. 1988]. Однако фразеологизированные модели предложений характерны не только для клишированных высказываний, но и для разговорной речи в целом (Мало ли чего хочется; Люди как люди; Не до грибов). По характеристике Н. Ю. Шведовой, это «построения, в которых связи и отношения компонентов с точки зрения живых грамматических правил оказываются необъяснимыми; [...] они специально предназначены для выражения субъективно-модальных значений» [Шведова (ред.) 1980: 217]. О значимости открытия «фразеологизированных предложений» (в работах Н. Ю. Шведовой и Д.Н. Шмелева рубежа 1950-х и 1960-х гг.) говорит тот факт, что в академической грамматике 1980 г. первое разделение простых предложений - это разделение «на схемы свободные и фразеологизированные» [Шведова (ред.) 1980: 93]. См. также: [Величко 1996], [Мечковская 2007], [Величко 2016], [Меликян 2001], [Меликян 2017].

4.2. Образность или лексико-семантическая неузуальность части коммуникативных клише. Образность или иной вид лексико-семантической идиоматичности коммуникативных клише (И концыь в воду!; Знает кошка, чье мясо съела; Не всё коту масленица) - это более сильное средство идиоматизации высказывания, чем фразеологизированность синтаксической модели; именно образность пословиц и речевых формул придают им обобщенность и прагматическу действенность. Вместе с тем образность не является облигаторным свойством коммуникативных клише (ср. речевые формулы Старость не радость, Поживем - увидим; Попытка не пытка и необразные пословицы из Даля: Запасливый нужды не знает; Запас беды не чинит; Запасливый лучше богатого). В паремиологических фондах разных народов образные паремии преобладают над необразными, но их удельный вес может быть разным. Так, по данным Н.И. Ефремовой [2003: 7], в 1000 немецких пословиц и поговорок образные паремии составили 70\%, а в 1000 русских паремий - $90 \%$.

\section{3. Взаимная независимость синтаксической и лексико-семантической} идиоматичности в коммуникативных клише. Фразеологизированный синтаксис усиливает идиоматичность высказывания, его синтаксическую цельность и складность, но не делает его воспроизводимым. Для воспроизводимости обязательна 
только лексическая неизменность конкретного высказывания. Синтаксическая идиоматичность может присутствовать не только в воспроизводимых высказываниях (Вот так клюква!), но и в высказываниях неклишированных (с переменной лексикой): А Ваня тебе чем не жених? И наоборот: по неидиоматическим моделям строятся как воспроизводимых высказывания (таково большинство пословиц: Быть бычку на веревочке), так и неклишированые высказывания (Cидеть тебе в запасных не знаю сколько; И ей он больше не жених). Наличие в воспрозводимых и невоспроизводимых высказываниях свойств синтаксической и лексико-семантической идиоматичности ниже показано в таблице.

\begin{tabular}{|l|l|l|}
\hline \multirow{2}{*}{$\begin{array}{r}\text { Синтаксическая } \\
\text { идиоматичност }\end{array}$} & \multicolumn{1}{|c|}{$\begin{array}{c}\text { Структурная схема предложения } \\
\text { восиоматичная } \\
\text { (фразеологизированная) }\end{array}$} & $\begin{array}{c}\text { неидиоматична } \\
\text { (не фразеологизированная) }\end{array}$ \\
\cline { 2 - 3 } $\begin{array}{l}\text { Клишированные высказывания } \\
\text { (лексическое наполнение оборо- } \\
\text { та постоянн) }\end{array}$ & $\begin{array}{l}\text { Вот так клюква! } \\
\text { Пропадай моя телега (голова). } \\
\text { Что в лоб, что по лбу. }\end{array}$ & $\begin{array}{l}\text { Голь на выдумки хитра. } \\
\text { Слезами горю не поможешь. } \\
\text { Быть бычку на веревочке. }\end{array}$ \\
\hline $\begin{array}{l}\text { Не клишированные (свободно со- } \\
\text { здаваемые в речи) высказывания }\end{array}$ & $\begin{array}{l}\text { Ай да плясун! Чем тебе Ваня } \\
\text { не жених? Люди как люди. }\end{array}$ & $\begin{array}{l}\text { Весна выдалась ранняя. } \\
\text { В следующий раз повезет. }\end{array}$ \\
\hline
\end{tabular}

Синтаксическая идиоматичность (в сравнении с лексической) менее заметна и слабее. Однако у нее свой прагматический эффект: такие структуры ощущаются говорящими как сжатые, неполные реплики в разговоре “своих людей”, понимающих друг друга с полуслова.

5. Воспроизводимость и идиоматичность как механизмы внутриуровневой консолидации языковых единиц. Свойства воспроизводимости и идиоматичности, частично взаимозависимые и по природе градуальные, в разной мере присущи уровням слов, словосочетаний и высказываний (предикативных единиц). Для слов названные свойства практически облигаторны: все слова, исключая потенциальные, воспроизводимы и идиоматичны, при этом полностью идиоматичны все непроизводные слова, частично идиоматичны - производные. В речевой синтагматике слов фраземы (воспроизводимые словосочетания) составляют незначительное меньшинство, однако их количество в абсолютных цифрах, с учетом массы неидиоматических и слабоидиоматических фразем, велико и, по всей вероятности, превышает количество лексем. Что касается уровня предикативных (коммуникативных) единиц, то здесь количество воспроизводимых единиц (относительное и абсолютное) минимально (в сравнении с уровнями слов и словосочетаний), при этом свойство идиоматичности характерно для высказываний в минимальной степени.

Каждое из свойств - воспроизводимость и идиоматичность - внутренне амбивалентно: с одной стороны, они придают языковым единицам стабильность, материальную компактность, предсказуемую эмфатичность (образных фразем и паремий) и иллокутивную определенность (паремий и речевых формул). Но, с другой стороны, воспроизводимые и идиоматичные средства языка, укорененные в речевой практике и ментальности народа, ограничивают мыслительные и коммуникативные горизонты говорящих, оставляя им свободу в выборе 
“подходящего" из наличных средств, но не в создании новых возможностей. Однако “гений языка” (или телеология его саморазвития) отмеряет для разных уровней разные пропорции клишированных языковых средств - от почти стопроцентной воспроизводимости слов до максимальной свободы говорящих в порождаемых высказываниях, включая новую образность и индивидуальные оттенки иллокуции речевых актов.

\section{Литература}

Величко А. В. Синтаксическая фразеология для русских и иностранцев. Учебное пособие. М. : Филол. ф-т МГУ, 1996.96 с.

Величко A.B. Предложения фразеологизированной структуры в русском языке. Структурно-семантическое и функционально-коммуникативное исследование / Монография. М. : МАКС Пресс, 2016. 416 с.

Виноградов В. В. Об основных типах фразеологических единиц в русском языке [1947] // Виноградов В.В. Избранные труды. Лексикология и лексикография. М. : Наука, 1977. С. 140-161.

Даль В.И. Пословицы русского народа. Сборник пословиц, поговорок, речений, присловий, чистоговорок, загадок, поверий и проч. [1861-1862]. 2-е изд., СПб.- М., 1879. T. I-II; М. : Русский язык, 1957.

Ефремова Н.И. Закономерности грамматической и лексической организации народной афористики (на материале немецких и русских паремий). Автореф. дис. ... канд. филол. наук. Минск: Белгосуниверситет, 2003. 20 с.

Иорданская Л.Н., Мельчук И.А. Смысл и сочетаемость в словаре. М. : ЯСК, 2007. 672 c.

Котова М. Ю. Русско-славянский словарь пословиц с английскими соответствиями / Под ред. проф. П. А. Дмитриева. СПб.: Изд-во СПбГУ, 2000. 360 с.

Крикман А. Паремиологические эксперименты Г. Л. Пермякова / Препринт КК I-40. Таллин: Академия наук Эстонской ССР. Отделение общественных наук, 1986. $60 \mathrm{c}$.

Меликян В. Ю. Словарь: Эмоционально-экспрессивные обороты живой речи. М. : Флинта; Наука, 2001. 240 с.

Меликян В.Ю. Современный русский язык: Синтаксическая фразеология. М. : Флинта; Наука, ${ }^{3} 2017.232$ с.

Мельчук И. А. О терминах “устойчивость” и “идиоматичность” // Вопросы языкознания, 1960, № 4. С. 73-80.

Мечковская Н.Б. Образная концептуализация градуально-количественных представлений в русской фразеологии // Jachnow H. etc. (Hrg.) Kognition, Sprache und phraseologische / parömiologische Graduierung. Wiesbaden: Harrasowitz Verlag, 2005. S. 58-153.

Мечковская Н.Б. О понятии “фразеологизм” применительно к номинативным и коммуникативным средствам языка // Hordy M. et al. (red.). Język. Człowiek. Dyskurs. Szcecin, 2007. S. 151-163. 
Шанский Н. М. Фразеология современного русского языка [1963]. М. : Просвещение, ${ }^{2} 1969.232$ с.

Шведова Н.Ю. (ред.) Русская грамматика. Т. ІІ. Синтаксис. М. : Наука, 1980. $712 \mathrm{c}$.

Fillmore Ch. J., Kay P., O'Connor C. Regularity and idiomaticity in grammatical constructions; the case of let alone // Language, 1988, vol. 64. P. 501-538.

Mel'čuk I. Phrasemes in Language and Phraseology in Linguistics // Everaert M. et al. (eds.). Idioms: Structural and Psychological Perspectives. Hillsdale (NJ); Hove, 1995. P. 167- 232.

Permjakov G.L. 300 allgemeingebrauchliche russische Sprichworter und Sprichwörtliche Redensarten. Ein illustriertes Nachschlagewerk für Deutschsprehende. M. : Russkij jazyk — Leipzig: VEB Verlag Enzyklopaedie, 1985. 160 S.

\author{
N. B. Mechkovskaya \\ Belarusian State University \\ (Belarus, Minsk) \\ nina.mechkovskaya@gmail.com
}

\title{
THE NOMINATIVE AND THE COMMUNICATIVE LEVELS OF THE LANGUAGE STRUCTURE: TO WHAT EXTENT THE REPRODUCIBILITY AND IDIOMATICITY OF UNITS ARE INHERENT TO THEM?
}

The article shows that the properties of reproducibility and idiomaticity of units take place at all semantic levels of the language structure (lexemes, word-combinations (mostly hypotactic), sentences), but the degree of their presence at different levels is different. For words, the named properties are practically obligatory: all words, except potential ones, are reproducible and idiomatic; what is more, non-derivative words are completely idiomatic, the derivatives are partly idiomatic, and the motivation of morphemic derivatives has an abstract logical-grammatical character (in contrast to the visual-figurative motivation of the phrasemes). In the syntagmatics of words, phrasemes constitute an insignificant minority of word-combinations, but their absolute amount, taking into account the mass of non-idiomatic and weakly idiomatic phrasemes, is large and, in all probability, exceeds the number of lexemes. At the level of predicative units, the number of reproducible units (relative and absolute) is minimal (in comparison with the levels of words and word-combinations); the property of idiomaticity is also characteristic of utterances to a minimum degree. The idiomatic nature of predicative clichés is created with the help of semantic mechanisms belonging to two levels of the language - grammar (the idiomaticity of a number of sentence models) and vocabulary (imagery or lexical-semantic non-reality). These mechanisms are not specific to predicative clichés; they are quite common in the freely created utterances. The proportions of freely created and cliched linguistic means, 
different for different levels, correspond to different functions of the language - to participate in thought processes and to be a reliable and economical means of communication.

Keywords: level structure of the language, reproducibility and idiomaticity in vocabulary, reproducible word-combinations (phrasemes), gradation of phrasemes according to the degree of idiomaticity, non-idiomatic and slightly idiomatic phrasemes, reproduced (cliched) utterances.

\section{References}

Velichko A. V. Sintaksicheskaya frazeologiya dlya russkikh i inostrantsev [Syntactic phraseology for Russian and foreigners]. Moscow, Moscow St. Univ. Publ. 1996. $96 \mathrm{p}$.

Velichko A.V. Predlozheniya frazeologizirovannoi struktury v rusckom yazyke. Strukturno-semanticheskoe i funktsional'no-kommunikativnoe issledovanie [Sentences of a phraseological structure in the Russian language. Structural-semantic and functional-communicative research]. Moscow, MAKS Press Publ., 2016. 416 p.

Vinogradov V. V. [On the main types of phraseological units in Russian] [1947] // Vinogradov V. V. Izbrannye trudy. Leksikologiya i leksikografiya [Selected works. Lexicology and lexicography]. Moscow, Nauka Publ., 1977, pp. 140-161. (In Russ.)

Dal' V. I. Poslovitsy russkogo naroda [Proverbs of the Russian people]. [1861-1862]. St. Petersburg — Moscow, 1879. Vol. I-II; Moscow, Russkii yazyk Publ., 1957.

Efremova N.I. Zakonomernosti grammaticheskoi i leksicheskoi organizatsii narodnoi aforistiki (na materiale nemetskikh i russkikh paremii). Avtoref. dis. ... kand. filol. nauk [Regularities of grammatical and lexical organization of popular aphoristics (on the basis of German and Russian paremia)]. Minsk, St. Univ. Publ., 2003. 20 p.

Fillmore Ch. J., Kay P., O'Connor C. Regularity and idiomaticity in grammatical constructions; the case of let alone. Language, 1988, vol. 64. pp. 501-538.

Iordanskaya L. N., Mel'chuk I. A. Smysl i sochetaemost'v slovare [Meaning and combinability in the dictionary]. Moscow, YaSK Publ., 2007. 672 p.

Kotova M.Yu. Russko-slavyanskii slovar' poslovits s angliiskimi sootvetstviyami [Russian-Slavic proverbial dictionary with English correspondences]. Dmitriev P.A. (ed.). St. Petersburg, St. Univ. Publ., 2000. 360 p.

Krikman A. Paremiologicheskie eksperimenty G.L. Permyakova [Paremiological experiments of G. L. Permyakov / Preprint KK I-40]. Tallin, Akademiya nauk Estonskoi SSR. Otdelenie obshchestvennykh nauk Publ., 1986. 60 p.

Melikyan V.Yu. Slovar': Emotsional'no-ekspressivnye oboroty zhivoi rechi [Vocabulary: Emotional-expressive expressions of living speech]. Moscow, Flinta; Nauka Publ., 2001. $240 \mathrm{p}$.

Melikyan V.Yu. Sovremennyi russkii yazyk: Sintaksicheskaya frazeologiya [Modern Russian: Syntactic Phraseology]. Moscow, Flinta; Nauka Publ., 2017. 232 p.

Mel'chuk I. A. [On the terms "stability" and "idiomaticity"]. Voprosy yazykoznaniya, 1960, no 4, pp. 73-80. (In Russ.) 
Mel'čuk I. Phrasemes in Language and Phraseology in Linguistics / Everaert M. et al. (eds.). Idioms: Structural and Psychological Perspectives. Hillsdale (NJ); Hove, 1995, pp. 167-232.

Mechkovskaya N. B. [Figurative conceptualization of gradual-quantitative representations in Russian phraseology] Jachnow H. ets. (Hrg.) Kognition, Sprache und phraseologische / parömiologische Graduierung [Cognition, language and phraseological / parmiological graduation]. Wiesbaden, Harrasowitz Verlag Publ., 2005, pp. 58-153. (In Russ.)

Mechkovskaya N.B. [On the concept of "phraseological" in relation to the nominative and communicative means of language]. Hordy M. et al. (red.). Jezzyk. Człowiek. Dyskurs [Language. Human. Discourse]. Szcecin, Univ. Publ., 2007, pp. 151-163. (In Russ.)

Permjakov G. L. 300 allgemeingebrauchliche russische Sprichworter und Sprichwörtliche Redensarten. Ein illustriertes Nachschlagewerk für Deutschsprehende [300 common Russian proverbs and proverbial sayings. An illustrated reference book for German-speaking people]. Moscow, Russkij jazyk — Leipzig, VEB Verlag Enzyklopaedie Publ., 1985. $160 \mathrm{p}$.

Shanskii N. M. Frazeologiya sovremennogo russkogo yazyka [Phraseology of the modern Russian language ]. [1963]. Moscow, Prosveshchenie Publ., 1969. 232 p.

Shvedova N.Yu. (ed.) Russkaya grammatika. T. II. Sintaksis [Russian grammar. Vol. II. Syntax]. Moscow, Nauka Publ., 1980. 712 p. 